\title{
Potential Use of Dragon Fruit and Taro leaves as functional food: a Review
}

\author{
Dnyaneshwar P Shekade ${ }^{1}$, Pravinkumar D Patil ${ }^{2}$, Gurunath V Mote ${ }^{3}$ Akashya K Sahoo $^{4}$ \\ ${ }^{1}$ Department of Food Technology, Shivaji University, Kolhapur, 416004, India. \\ ${ }^{2}$ Department of Chemical Technology, Shivaji University, Kolhapur, 416004, India. \\ ${ }^{3}$ Department of Food Technology, Shivaji University, Kolhapur, 416004, India. \\ ${ }^{4}$ Department of Food Technology, Shivaji University, Kolhapur, 416004, India.
}

\begin{tabular}{|c|c|}
\hline ARTICLE INFO & ABSTRACT \\
\hline $\begin{array}{l}\text { Keywords: } \\
\text { Dragon fruit, Taro } \\
\text { leaves, drying, } \\
\text { antioxidant activity, } \\
\text { biochemical compounds }\end{array}$ & $\begin{array}{l}\text { Fruits and vegetables are important constituents of our diet which } \\
\text { provide significant quantities of nutrients especially vitamins, } \\
\text { minerals and fiber. Daily consumption of fruits and vegetables } \\
\text { reduce the risk of cancer, heart disease, premature aging and stress. } \\
\text { 'Fruit and vegetable based dried powders are one of the best sources } \\
\text { of vitamins, minerals, fibers and valuable bioactive compounds } \\
\text { which are essential for human health. The health benefits associated } \\
\text { with fruits and vegetables on a daily basis are related to the ingestion } \\
\text { of bioactive components. Taking into consideration of associated } \\
\text { health benefits on present work deals with a newly development of } \\
\text { functional food powder prepared by using dragon fruit and taro } \\
\text { leaves because dragon fruit and taro leaves contain vitamin C and B, } \\
\text { and phytochemicals which are essential to maintain good health. } \\
\text { These two possess various nutraceutical activities such as } \\
\text { antioxidant, anticancer, antifungal, curing of various diseases like } \\
\text { cancer, cardiovascular disease, coronary heart disease etc. The future } \\
\text { development of functional foods will require contributions from } \\
\text { basic and applied scientists in academia, government and industry. }\end{array}$ \\
\hline
\end{tabular}

\section{Introduction:}

India is the world's largest producer of many fresh fruits and vegetables. Its vast geographical area coupled with varied climate conditions facilitates to grow a variety of fruits and vegetables. We produced around 81.285 MT fruits in annual (Rais and Sheoran, 2015).It has been found that 3040 percent of fruits and vegetables are wasted due to post harvest losses. Waste percentages in each step of the food supply chain in India is the cause of low availability of fruits and vegetables for consumers and the need for import of them in spite of India being second largest producer. Though we are the world's second largest fruit and vegetable producer encounters a waste of close to $25 \%$ worth of produce (Rais and Sheoran, 2015). 
Fruits and vegetables are important constituents of our diet and provide significant quantities of nutrients especially vitamins, sugars, minerals and fiber. Daily consumption of fruits and vegetables reduces the risk of cancer, heart disease, premature aging, stress and fatigue primarily due to the integrated action of oxygen radical scavengers such as $\beta$-carotene and ascorbic acid plus calcium and dietary fiber. Due to the perishable nature of the fruits and vegetables they require immediate processing to avoid post-harvest losses and add the value. This may be attributed to change in dietary habits, taste preferences and the way of life of present-day consumers. Fruits and vegetables have higher nutritional, medicinal and calorific values. Fruit and Vegetable based Powder is one of the best source of vitamins minerals and valuable bioactive compounds which are essential for human health (Sindumathi and Premalatha, 2013).

The health benefits associated with fruit and Vegetables on a daily basis are related to the ingestion of bioactive components. The composition of a fruit and Vegetables depends on the variety, origin and growing conditions of the fruit. There are critical to good health, and certainly good for all age categories as it forms an important portion of a healthy diet. There are well known for their medicinal properties like antihypertensive, antihyperlipidemic, antihyperglycemic, antipyretic, wound healing, antitumor, anticancer, anti-inflammatory, etc. (Jan and Dorcus, 2012).

Functional foods are foods that have a potentially positive effect on health beyond basic nutrition. Proponents of functional foods say they promote optimal health and help reduce the risk of disease. Functional foods and their health benefits beyond individual nutrients present challenges to the traditional 'nutrition' approach to foods. Epidemiological studies suggest that regular or increased consumption of fruits may promote general health and well-being as well as reduce the risk of chronic diseases (Sun-Waterhouse, .2011).

Overwhelming evidence from epidemiological, in vivo, in vitro, and clinical trial data indicates that a plant-based diet can reduce the risk of chronic disease, particularly cancer. In 1992, a review of 200 epidemiological studies (Block et al., 1992) showed that cancer risk in people consuming diets high in fruits and vegetables was only one-half that in those consuming few of these foods. It is now clear that there are components in a plant-based diet other than traditional nutrients that can reduce cancer risk. Steinmetz and Potter (1991a) identified more than a dozen classes of these biologically active plant chemicals, now known as "phytochemicals."

Consumer acceptance of the concept of functional foods, and a better understanding of its determinants, are widely recognized as key success factors for market orientation, consumer-led product development, and successfully negotiating market opportunities. It was mainly the advances in understanding the relationship between nutrition and health that resulted in the development of the concept of functional foods, which means a practical and new approach to achieve optimal health status by promoting the state of well-being and possibly reducing the risk of disease. Moreover, it is beyond doubt that persuading people to make healthier food choices 
would provide substantial (public) health effects (e.g. decreased mortality, and increased quality of life), therefore it is a common economic and public interest.

The Functional food is in reach in nutritional and helpful to the human health. Consuming the nutritional rich powder regularly reduces the risk of like cancer, heart disease, cardiovascular disease, etc.

\section{Relevance of the work}

Considering the importance and necessity of the research efforts towards human health care, we have proposed to carry out the research work on the two sources namely Dragon Fruit and Taro Leaves.

Dragon Fruit (Hylocereus polyrhizus) or pitaya is the fruit of several different cactus species indigenous to the Americas. Pitaya usually refers to fruit of the genus Steno cereus, while pitahaya or dragon fruit refers to fruit of the genus Hylocereus, both in the Cactaceae family. The dragon fruit is cultivated in Southeast Asia, Florida, the Caribbean, Australia, and rough and subtropical world regions. These fruits are commonly known in English as "dragon fruit", reflecting its vernacular Asian Ames. The names pitahaya and pitaya derive from Mexico, and pitaya roja in Central America and northern South America, possibly relating to pitahaya for names of tall cacti species with flowering fruit. (Tonny et al., 2017)

Dragon fruit or pitaya belongs to the Cactaceae family from the subfamily Cactoidea of the tribe Cactea. In Malaysia, the pitaya or dragon fruit is commonly called as "buah naga". Among the pitaya species (Hylocereus polyrhizus) fruits are edible and it has a great source of vitamin $\mathrm{C}$ and water soluble fiber. Dragon Fruit is a small fruit climbing cactus that has received world-wide recognition as an ornamental plant for its large, scented night-blooming flowers. The red skin fruit weighed up to $1 \mathrm{~kg}$ has translucent dark-red flesh considered as a rich source of nutrients and minerals such as vitamin B1, vitamin B2, vitamin B3 and vitamin C, protein, fat, carbohydrate, crude fiber, flavonoid, thiamin, niacin, pyridoxine, kobalamin, glucose, phenolic, betacyanins, polyphenol, carotene, phosphorus, iron and phytoalbumin. Syukri et,al., (2012). (Hylocereus polyrhizus) is rich in fibers, vitamin $\mathrm{C}$, minerals and phytoalbumins which are highly valued for their antioxidant properties. The dragon fruit helps the digestive process, prevent colon cancer and diabetes, neutralize toxic substances such as heavy metal, reduce cholesterol levels and high blood pressure and consumed regularly the dragon fruit can help against asthma and cough. There is also rich with potassium, protein, fiber, sodium and calcium which are better for health than other fruits life of present-day consumers. (Tonny et al., 2017)

The other source is a Taro Leaves

Taro (Colocasia esculent) is a genus of flowering plants in the family Araceae, native to southeastern Asia and the Indian subcontinent. Some species are widely cultivated and naturalized 
in other tropical and subtropical regions. Taro (Colocasia esculent) is a tropical plant grown primarily for its edible corms, the root vegetables most commonly known as taro. It is a food staple in African, Oceanic and Indian cultures and is believed to have been one of the earliest cultivated plants. The generic name is derived from the ancient Greek word kolokasion, which in the Greek botanist Dioscorides (1st century AD) meant the edible roots of both Colocasia esculenta and Nelumbo nucifera. It is thought that the edible roots of Taro have been cultivated in Asia for more than ten thousand years.

Taro leaves are a rich source of protein, ascorbic acid, dietary fiber, and other important minerals including, thiamin, riboflavin, iron, phosphorus, zinc, vitamin B6, vitamin C, niacin, potassium, copper, and manganese. Some studies have suggested that they also have analgesic and antiinflammatory properties, antifungal Properties, Reported by Krishnapriya et al., (2017). Microorganism to grow so when concentration of water in the food. Moisture can be removed by the application of heat as in drying process. Fruit and vegetables are preserved in the powder from in long time. The sun drying or mechanical drying used in fruit and vegetables drying process then some time used in mechanically process because this method is time consuming and maintain time, temperature and humidity in drying process. The important benefit of drying is to maintain the nutritional value for long term (R.P. Srivastava and S. Kumar, 2002).

In the last decades consumer demands in the field of food production has changed considerably. Consumers more and more believe that foods contribute directly to their health (Mollet \& Rowland, 2002; Young, 2000). Today foods are not intended to only satisfy hunger and to provide necessary nutrients for humans but also to prevent nutrition-related diseases and improve physical and mental well-being of the consumers.

Functional food is a food given an additional function (often one related to health-promotion or disease prevention) by adding new ingredients or more of existing ingredients. Functional foods may be "designed to have physiological benefits and/or reduce the risk of chronic disease beyond basic nutritional functions, and may be similar in appearance to conventional food and consumed as part of a regular diet". Moreover, one could think of a new product development through blending in the form of a Functional (Nutritive) Powder, which may also be used as a Nutritive Powder.

\section{Functional food}

Typically, a food marketed as functional contains added, technologically developed ingredients with a specific health benefit (Niva, 2007). Although the term "functional food" has already been defined several times (Roberfroid, 2002), In most countries there is no legislative definition of the term and drawing a border line between conventional and functional foods is challenging even for nutrition and food experts. 
Work carried out by other researchers

Most early developments of functional foods were those of fortified with vitamins and/or minerals such as vitamin C, vitamin E, folic acid, zinc, iron, and calcium (Sloan, 2000). Subsequently, the focus shifted to foods fortified with various micronutrients such as omega-3 fatty acid, phytosterol, and soluble fiber to promote good health or to prevent diseases such as cancers (Sloan, 2002). More recently, food companies have taken further steps to develop food products that offer multiple health benefits in a single food (Sloan, 2004). Moreover, it is beyond doubt that persuading people to make healthier food choices would provide substantial (public) health effects (e.g. decreased mortality, and increased quality of life), therefore it is a common economic and public interest. (Siro et al., 2008)

Dragon fruit (Hylecereus polyhizus) is well known for the rich nutrient contents and it is commercially available worldwide for improving many health problems. Several studies show proximity value of pitaya fruits but the nutrient composition of the stem has not been intensively studied.

Ruzainah et al., 2009, has studied that the dragon fruit is a rich source of vitamins, minerals and anti-oxidants and consuming it regularly makes it highly beneficial for us to lead a healthy life. These nutrients help in protecting our body from potentially dangerous health conditions like cancer and heart diseases. This fruit is also an excellent source of minerals like calcium, iron and phosphorus and also important vitamins like vitamin $\mathrm{C}$ and the $\mathrm{B}$ group vitamins. The phytoalbumins present in the fruits have high anti-oxidant properties which fights the development and growth of cancer causing cells the bioactive compound content of dragon fruit in powder remains unknown. Tenore et al., (2009) has suggested that dragon fruit contains phytochemicals that are good for the body, such as polyphenols and flavonoids. Rebecca et al. showed that the total polyphenol content in dragon fruit flesh is as high as $86.129 \pm 17.016$ (mg/0.5 g gallic acid), while the total flavonoid content can reach $2.3 \pm 0.20$ (mg gG1 catechin). However, the bioactive compound content of dragon fruit in powder remains unknown. The powder has a long shelf life and a high economic value and could serve as a functional food that can be added to a variety of processed food products.

Tonny et al., (2017) has studied the cardiovascular diseases, diabetes, cancer, arthritis and many other diseases may be caused by genetic or age-related factors. However, personal lifestyle, including dietary intake and physical activity, along with environmental surroundings, may also contribute to disease risk. The powder has a long shelf life and a high economic value and could serve as a functional food that can be added to a variety of processed food products. The objective of this study was to identify the total bioactive compounds in dragon fruit powder. 
Ghiselli et al., (2017) mentioned that the free radicals produced by our body induce oxidative stress and are related to several other harmful effects, including coronary heart diseases, neurodegenerative disorders and aging. Consumption of fresh fruits and vegetables is important to help prevent the action of free radicals. For many years, fruits have become an area of investigation due to their bioactive compounds, which are beneficial for human health.

(Tonny et al., 2017) has Research shows that ripe dragon fruit contains numerous total dissolved solids that are rich in organic acids, proteins and other minerals such as potassium, magnesium, calcium and vitamin C. Various betacyanins and betaxanthins have shown the ability to capture free radicals which in turn contributes to the interest in red dragon fruit consumption as a source of antioxidants. Furthermore, another study mentioned that dragon fruit has strong antiradical properties with other phenolic compounds, but its characteristics have not been reported. Tenore et al. suggested that red dragon fruit contains phytochemicals that are good for the body, such as polyphenols and flavonoids.

Temesgen et al., (2016) has studied that the Taro is also a good source of thiamin, riboflavin, iron, phosphorus and zinc and a very good source of vitamin B6, vitamin C, niacin, potassium, copper and manganese. Taro also contains greater amounts of vitamin $\mathrm{C}$ and Protein. Traditional knowledge of medicine has long been used since ages for curing various human ailments. About $60-80 \%$ world populations still rely on plant based medicines. Through the traditional Indian systems of medicine has a long history of use, yet they lack adequate scientific knowledge (Shrivastava et al., 2010). Through phytochemical screening one could detect the various important compounds which could be used as the base of modern drugs that curing various diseases.

In Asia, the leaves of taro have been reported to be rich in minerals like $\mathrm{Ca}, \mathrm{P}, \mathrm{Fe}$, and vitamins: vitamin $\mathrm{C}$, thiamine, riboflavin and niacin. The high level of dietary fiber found in the taro leaf are also advantageous for their active role in the regulation intestinal transit, increasing dietary bulk and faeces consistency due to their ability to absorb water (Saldanha, 1995). Most rural peoples suffer from malnutrition not because of the economic status but because of inability to utilize the available nutritious raw materials to meet their daily requirements (Annan and Plahar, 1995). Currently, zinc deficiency is widespread and affects the health and well-being of populations of the developing countries worldwide. Since taro leaf, is one of the few non-animal sources of zinc, its utilization should therefore be pursued to help in the alleviation of zinc deficiency which is associated with stunting of children (Walker, 1990). While taro has many nutritional, economic and health attributes, by regularly consuming freshly cooked taro, one is sure to keep off dangerous disease like cancer. This is due to the presence of vitamin $\mathrm{C}$ in them. Vitamin $\mathrm{C}$ is a protective and powerful antioxidant that can prevent common ailments like Cold Cough to even certain cancers. The leaves of taro contain enormous amounts of Phenolic and carotenoids compounds, which tend to exhibit potent antioxidant properties. Both these chemical compounds help the body to fight 
free radicals and takes care of the cells from further damage and oxidative stress. Taro has low levels of saturated fat, and that is the major reason why it is claimed to be a healthy food for the heart. The fiber content present in them stops the accretion of cholesterol and fat in the blood streams whereas the potassium assists in maintaining a normal blood pressure. It lowers the homocysteines levels in the blood and saves you from heart problems and strokes. So, if you don't want to harden your arteries, make sure to consume this vegetable on a regular basis. The Dried Taro Leaves (Colocasia Esculenta) Powder is a kind of loose white powder. The ingredients are from the tender fruit which are planted in GAP certified planting base and process strictly under the rules of international regulations. It's $100 \%$ pure nature nutrient without any additives, and having natural fragrant flavors. It can be used to make various Foods or consumed directly Powder as Nutritional Purpose and desserts. It is also an ideal consistency for dusting onto puddings.

Functional food is a food given an additional function (often one related to health-promotion or disease prevention) by adding new ingredients or more of existing ingredients. Functional foods may be "designed to have physiological benefits or reduce the risk of chronic disease beyond basic nutritional functions, and may be similar in appearance to conventional food and consumed as part of a regular diet". (Siro et al., 2008).

The Dragon Fruit powder and taro leaves dried powder is good for Human health from Nutritive Purpose and Consuming Daily basis of Powder which helps to reduces some types of disease. Like cancer, colon cancer, cardiovascular disease, heart related disease.

\section{Process Flowchart:}

Raw material:

Dragon Fruits: will be purchased from the local market and necessary pre- treatments such as washing, grading, sorting etc.

Taro leaves: will be collected from department of botany Shivaji University Kolhapur and necessary pre-treatments such as washing, grading, sorting etc. Sugar: will be purchased from the local market in Kolhapur and further used of nutritional purpose. Dragon fruit and Taro leaves would be used for preparation of Functional Powder for Nutritional purpose.

Preparation of Powder: The Dragon fruit and Taro leaves will be prepared using method explained by Tonny et al., (2017) and Alcantara et al., (2013) described by process Fig. 1 and Fig. 2 respectively with slight modification 
Preparation of Dragon Fruit powder:

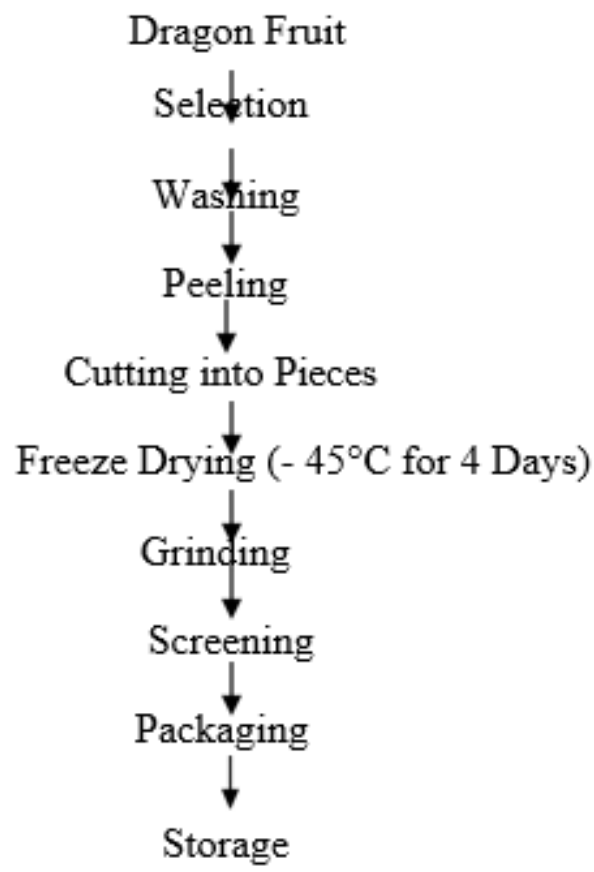

Fig.1: Preparation of Dragon Fruit Powder (Tonny et al., (2017) 
Preparation of Taro Leaves Powder: Taro leaves Powder will be prepared by the method mentioned below

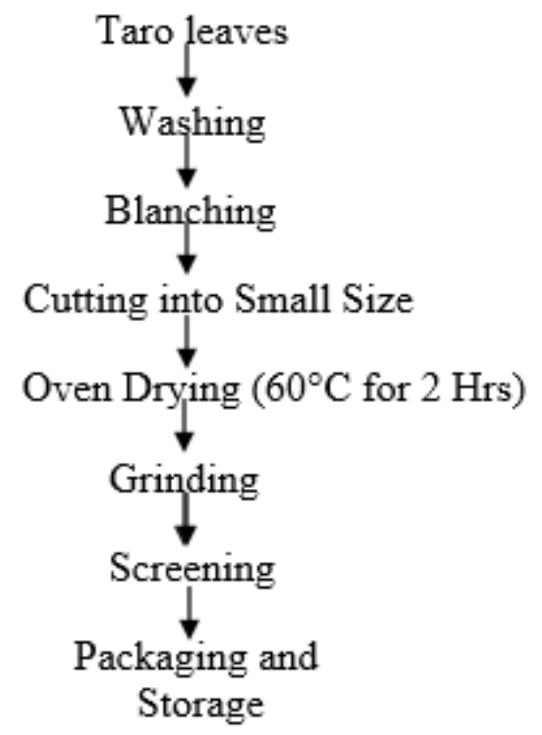

Fig.2: Preparation of Taro Leaves Powder (Alcantara et al., (2013).

Development of Functional Powder: The Mixing Functional Powder will be prepared by Taro Leaves Powder and Dragon fruit Powder according to method described below with slight modifications

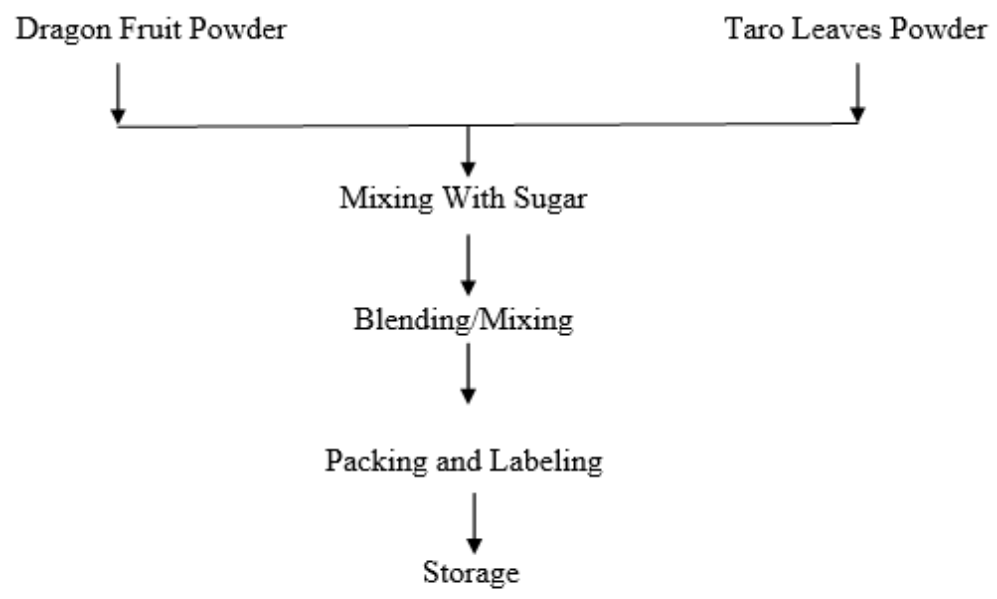

Fig.3: Development of Functional Powder. 


\section{Conclusion:}

There is no doubt that functional foods generate one of the most promising and dynamically developing segments of food industry. There are several factors supporting the inflow of functional products like the increasing consumer awareness in combination with new advances in various scientific domains. Functional foods have been developed virtually in all food categories, Different surveys showed that consumer acceptance of functional foods is far from being unconditional, with one of the main conditions for acceptance pertaining to taste, besides, product quality, price, convenience and trustworthiness of health claims. As a rule, consumers seem to evaluate functional foods first and foremost as foods. Functional benefits may provide added value to consumers but cannot outweigh the sensory properties of foods. By purchasing functional foods in general consumers may achieve a modern and positive impression of themselves.

The expert report identifies several areas where changes are needed to further encourage the development of functional foods. The following recommendations are particularly critical Expand research into traditional nutrients, other bioactive food components, and the intersection of genomics and molecular nutrition. Continued basic and applied nutritional research must further explore the roles and mechanisms of action for traditional nutrients. In addition to traditional nutrients, other bioactive food components with the ability to improve health must be identified and their efficacy proven. The intersection of genomics and molecular nutrition presents opportunities for more definitively understanding diet and health in individuals and population groups, with the potential for personalized diets for optimal health.

The future development of functional foods will require contributions from basic and applied scientists in academia, government, and industry. Consumers want and need these products, and mechanisms must be found to foster their availability.

There for the success in preparing an innovative functional food Powder from these two selected sources will have the significant impact in the field of health care. Thus the topic is with great deal of scope for the related studies. We are sure that we will come out with some concrete solutions for the problem of health issues, innovations in crops for formers etc. it is obvious that the dissertation work carried out on such an interesting topic will help the society. It also will help the agriculture and forming sector of the country.

The ultimate success of functional foods will depend on delivering bioactive components in a predictable and assured manner to effectively reduce the risk of disease and/or improve body structure or function.

Dragon Fruits and Taro leaves contain Vitamin C and B, phytochemicals which are essential to maintain good health. They possess various activities such as, antioxidant, anticancer, antifungal, curing of various diseases like cancer, cardiovascular disease, Coronary heart disease etc. Blending of Dragon fruits Powder and Taro leaves Powder explores the opportunities to prepare 
the Functional (Nutritive) Powder which are rich in Vitamin C, phytochemicals. Blending of Powder also helps to develop delightful, delicious Functional Powder with excellent Functional and a nutritional property which may be also help of Health and reduces some type of Dangerous disease like colon cancer, cardiovascular disease and Coronary heart Disease. The Dragon Fruit powder and taro leaves dried powder is good for Human health from Nutritive Purpose and Consuming Daily basis of Powder which helps to reduces some types of disease.

\section{Reference:}

A.O.A.C. 2000. Official Methods of Analysis. Association of Official Analytical Chemists, Washington, D. C.USA.17th Edition.

Alcantara, M., Hurtada, A., \& Dizon, I. (2013).The nutritional value and phytochemical components of taro [Colocasia esculenta (L.) Schott] powder and its selected processed foods. Nutrition \& Food Sciences.

Block, G., Patterson, B., \& Subar, A. (1992). Fruit, vegetables, and cancer prevention: a review of the epidemiological evidence. Nutrition and cancer, 18(1), 1-29.

Elizabeth, L. (1977). Laboratory Methods for Sensory Evaluation of Food. Canada Department of Agriculture, Ottawa, Canada, 21-23.

Ferreira, M. S., Santos, M. C., Moro, T. M., Basto, G. J., Andrade, R. M., \& Gonçalves, É. C. (2015). Formulation and characterization of functional foods based on fruit and vegetable residue flour. Journal of food science and technology, 52(2), 822-830.

Hasler, C. M. (1998). Functional foods: their role in disease prevention and health promotion. FOOD TECHNOLOGY-CHAMPAIGN THEN CHICAGO-, 52, 63-147.

Hasler, C. M. (1998). Functional foods: their role in disease prevention and health promotion. FOOD TECHNOLOGY-CHAMPAIGN THEN CHICAGO-, 52, 63-147.

Jan, A., \& Masih, E. D. (2012). Development and quality evaluation of pineapple juice blend with carrot and orange juice. International Journal of Scientific and Research Publications, 2(8), 1-8.

Kang, H. J., Chawla, S. P., Jo, C., Kwon, J. H., \& Byun, M. W. (2006). Studies on the development of functional powder from citrus peel. Bioresource technology, 97(4), 614-620.

Krishnapriya, T. V., \& Suganthi, A. (2017). Biochemical and phytochemical analysis of colocasia esculenta (L.) Schott tubers. International Journal of Research in Pharmacy and Pharmaceutical Sciences, 2(3), 21-25.

Liaotrakoon, W. (2013). Characterization of dragon fruit (Hylocereus spp.) components with valorization potential (Doctoral dissertation, Ghent University).

Liu, R. H. (2003). Health benefits of fruit and vegetables are from additive and synergistic combinations of phytochemicals. The American journal of clinical nutrition, 78(3), 517S-520S. 
Lourith, N. A. T. T. A. Y. A., \& Kanlayavattanakul, M. A. Y. U. R. E. E. (2013). Antioxidant and stability of dragon fruit peel colour. Agro. Food Ind. Hi-Tech, 24, 56-58.

Maigoda, T. C., Sulaeman, A., Setiawan, B., \& Wibawan, I. W. (2016). Effects of red dragon fruits (Hylocereus polyrhizus) powder and swimming exercise on inflammation, oxidative stress markers, and physical fitness in male obesity rats (Sprague dawley). IJSBAR, 25(1), 123-141.

Narayana Rao, M., Shurpalekar, K. S., \& Sundaravalli, O. E. (1970). Purification and properties of an amylase inhibitor from colocasia (Colocasia esculenta) tubers. Indian Journal of Biochemistry, 7, 241-243.

Nip, W. K. (1990). Taro food products.

Njintang, Y. N., Scher, J., \& Mbofung, C. M. F. (2008). Physicochemical, thermal properties and microstructure of six varieties of taro (Colocasia esculenta L. Schott) flours and starches. Journal of Food Engineering, 86(2), 294

Nurul, S. R., \& Asmah, R. (2014). Variability in nutritional composition and phytochemical properties of red pitaya (Hylocereus polyrhizus) from Malaysia and Australia. International Food Research Journal, 21(4).

Patil, B. R., \& Ageely, H. M. (2011). Antihepatotoxic activity of Colocasia esculenta leaf juice. International Journal of Advanced Biotechnology \& Research, 2(2), 296-304.

Rais, M., and Sheoran, A. (2015). Scope of supply chain management in fruits and vegetables in India. J. Food Process. Technology, 6(3).

Rasmussen, M., Krølner, R., Klepp, K. I., Lytle, L., Brug, J., Bere, E., \& Due, P. (2006). Determinants of fruit and vegetable consumption among children and adolescents: a review of the literature. Part I: quantitative studies. International Journal of Behavioral Nutrition and Physical Activity, 3(1), 22.

Siro, I., Kapolna, E., Kápolna, B., \& Lugasi, A. (2008). Functional food. Product development, marketing and consumer acceptance-A review. Appetite, 51(3), 456-467.

Srivastava, R. P., \& Kumar, S. (2002). Fruit and vegetable preservation: Principles and practices. CBS Publishers \& Distributors Pvt. Limited.

Sun-Waterhouse, D. (2011). The development of fruit-based functional foods targeting the health and wellness market: a review. International Journal of Food Science \& Technology, 46(5), 899920.

Temesgen, M., Retta, N., \& Tesfaye, E. (2016). Effect of pre-curding on nutritional and antinutritional composition of taro (Colocasia esculenta L.) Leaf. Inter J Food Sci Nutri, 1(1), 05-11. VH, E. S., Utomo, S. B., Syukri, Y., \& Redjeki, T. (2012). Phytochemical screening and analysis polyphenolic antioxidant activity of methanolic extract of white dragon fruit (Hylocereus undatus). Indonesian Journal of Pharmacy, 60-64. 